\title{
PERANCANGAN SISTEM PAKAR UNTUK PENGENDALIAN KUALITAS PADA SPAREPART DENGAN SISTEM DIE CASTING (STUDI KASUS PADA PT. SJA)
}

\author{
Ahmad, Lithrone Laricha dan Felisia Wijaya \\ Program Studi Teknik Industri Universitas Tarumanagara \\ e-mail: laricha_salomon@yahoo.com
}

\begin{abstract}
ABSTRAK
Proses pengendalian kualitas dan pengawasan terhadap pengendalian kualitas harus ditangani oleh seorang pakar atau seorang ahli secara cepat dan tepat dalam mengatasi suatu masalah. Namun kenyataan di lapangan, seorang pakar tidak dapat hadir dan menyelesaikan semua masalah tepat waktu pada saat dibutuhkan. Tujuan dari penelitian ini adalah menganalisis faktor-faktor yang dapat menyebabkan kecacatan produk, memberikan informasi tentang hal-hal yang harus diperhatikan dalam pengendalian kualitas pada bahan baku dan proses produksi, memberikan informasi berupa tindakan yang dilakukan dalam menghadapi masalah tentang pengendalian kualitas yang ada, memberikan usulan rancangan sistem pakar untuk mendukung proses pengendalian kualitas dengan menggunakan sistem pakar yang disesuaikan pada penyebab cacat yang terjadi, hal-hal yang harus diperhatikan pada pengendalian kualitas bahan baku serta proses produksi, dan upaya menghadapi cacat pada produk yang terjadi. Untuk memenuhi kebutuhan tersebut maka dilakukan pengolahan data menggunakan peta kendali dan diagram pareto kemudian dilanjutkan dengan analisis penyebab cacat yang terjadi menggunakan fishbone diagram dan FMEA. Semua informasi yang didapat mengenai pengendalian kualitas untuk setiap prosesnya akan disajikan dalam bentuk sistem pakar. Dari penelitian ini dapat disimpulkan terdapat tiga jenis cacat yang ada pada PT. SJA, yaitu cacat visual. Keropos, dan dimensi. Masingmasing memiliki faktor penyebab yang berbeda-beda.
\end{abstract}

Kata Kunci: Sistem Pakar, Pengendalian Kualitas, FMEA

\begin{abstract}
The process of quality control and supervision of quality control should be handled by an expert or an expert quickly and appropriately in dealing with a problem. But the reality on the ground, an expert was unable to attend and solve all the problems on time when needed. The aim of this study was to analyze the factors that can cause disability products, provide information on matters to be considered in the quality control on raw materials and production processes, provide information in the form of the action taken in dealing with problems of quality control that is, giving the proposed design of an expert system to support the quality control process by using an expert system that is tailored to the cause of the defect, the things that must be considered in the quality control of raw materials and production processes, and attempt to deal with defects in products occurs. To meet these needs, the data processing is done using a control chart and Pareto diagram is then followed by analysis of the causes of defects that occur using the fishbone diagram and FMEA. All the information obtained regarding the quality control of each process will be presented in the form of an expert system. From this research it can be concluded that there are three types of defects that exist in PT. SJA, ie visual defects, porous, and dimensions. Each has a causative factor different.
\end{abstract}

Keywords: Expert System, Quality Control, FMEA

\section{PENDAHULUAN}

Pengendalian kualitas pada produk sangat penting dilakukan untuk menurunkan tingkat kegagalan pada produk jadi [1]. Pengendalian kualitas harus dilakukan pada bahan baku, proses produksi, dan produk akhir [2]. Pengawasan terhadap pengendalian kualitas pada suatu perusahaan harus ditangani oleh seorang pakar atau seorang ahli yang dapat secara cepat dan tepat dalam mengatasi suatu masalah. Namun kenyataan di lapangan, seorang pakar tidak dapat hadir dan menyelesaikan semua masalah tepat waktu dan saat dibutuhkan. Oleh sebab itu, perusahaan memerlukan sebuah sistem yang memiliki pengetahuan dan kemampuan setara dengan seorang pakar untuk dapat menyelesaikan suatu masalah yang terjadi juga agar dapat meningkatkan pengendalian kualitas agar dapat meminimasi jumlah cacat produk. Sistem yang dapat digunakan dalam hal ini adalah sistem pakar yang menggunakan bahasa pemrograman [3].

Tujuan dari penelitian ini adalah menganalisis faktor-faktor yang dapat menyebabkan kecacatan produk yang terjadi, memberikan informasi berupa pengambilan keputusan atau tindakan yang dilakukan seorang pakar dalam menghadapi masalah tentang pengendalian kualitas yang ada, 
memberikan informasi tentang hal-hal yang harus diperhatikan dalam pengendalian kualitas pada bahan baku dan proses produksi, dan memberikan usulan rancangan sistem pakar untuk menyempurnakan proses pengendalian kualitas dengan menggunakan sistem pakar yang disesuaikan pada kondisi dan situasi pada terhadap pengendalian kualitas dan pengambilan keputusan yang biasanya dilakukan oleh seorang pakar. Dengan batasan, yaitu penelitian perancangan sistem pakar tertuju pada bahan baku, proses produksi, dan produk akhir berdasarkan jenis cacat terbesar.

\section{TINJAUAN PUSTAKA \\ Pengendalian Kualitas}

Pengertian kualitas menurut Feigenbaum adalah keseluruhan karakteristik produk dan jasa yang meliputi marketing, engineering, manufacture, dan maintenance dimana produk dan jasa tersebut dalam pemakainannya akan sesuai dengan kebutuhan dan harapan pelanggan. Pengertian dari kata "kendali" itu sendiri adalah kegiatan mengarahkan, mempengaruhi, verifikasi dan perbaikan untuk menjamin penerimaan produk tertentu sesuai rancangan dan spesifikasi [4].

Dapat disimpulkan bahwa, pengendalian kualitas adalah suatu kegiatan dalam mengarahkan atau memperbaiki suatu mutu produk yang berkaitan dengan manufaktur, orang, lingkungan, proses dan pelayanan sesuai dengan keinginan atau harapan serta kebutuhan dari konsumen sekarang dan yang akan datang. Terdapat enam alat dalam pengendalian kualitas, yaitu pareto diagram, diagram sebab akibat, check sheet, histogram, scaterred diagram, peta kendali.

\section{Peta Kendali}

Peta kendali adalah suatau alat yang digunakan untuk menganalisis suatu proses yang sedang berjalan. Nilai dari karakteristik kualitas diplot sepanjang garis vertikal, dan garis horizontal mewakili sampel atau subgrup berdasarkan waktu dimana karakteristik dari kualitas ditemukan [5]. Peta kendali digunakan untuk membantu dalam mendeteksi ada atau tidaknya penyimpangan yang terjadi dengan menetapkan batas kendali, yaitu batas kendali atas (BKA) adalah garis batas atas untuk suatu nilai penyimpangan yang masih diperbolehkan, garis tengah adalah garis yang melambangkan bahwa tidak adanya penyimpangan dari sampel, dan batas kendali bawah (BKB) adalah garis batas bawah untuk suatu nilai penyimpangan.

Peta kendali dibagi menjadi dua yaitu peta kendali untuk data variabel dan peta kendali untuk data atribut. Peta kendali untuk data atribut biasanya didasarkan pada apakah produk tersebut cacat atau tidak. Klasifikasi ini dapat bersumber pada proporsi jumlah produk cacat terhadap ukuran sampel (peta p) atau dari jumlah cacat yang ada pada satu unit produk didalam sampel (peta c). Rumus untuk peta p itu sendiri adalah

$$
\begin{aligned}
& \text { UCLp = p-bar }+3 \sqrt{ }(\text { p-bar }(1-p-b a r) / n) \\
& \text { CL }=\text { p-bar } \\
& \text { LCLp = p-bar }-3 \sqrt{ }(\text { p-bar }(1-p-b a r) / n)
\end{aligned}
$$

\section{Decision support system}

Konsep Decision Support System pertama kali digunakan oleh Michael S. Scott Morton pada awal tahun 1970 dengan menggunakan istilah management decision system. Konsep ini merupakan suatu mekanisme berbasis pada penggunaan data dan model untuk memecahkan permasalahan yang tidak terstruktur [6]. DSS sendiri memiliki karakteristik yaitu

1. Penekanan pada fleksibilitas, memiliki kemampuan adaptif terhadap perubahan serta respon yang cepat.

2. Kemampuan pengendalian oleh pengguna.

3. Fokus pada pengambilan keputusan yang ditujukan bagi manajemen tingkat atas.

4. Mampu mendukung cara pengambilan keputusan yang berbeda oleh setiap pengguna.

\section{Sistem Pakar}

Sistem pakar adalah suatu sistem yang berusaha mengadopsi pengetahuan manusia ke komputer, agar komputer dapat menyelesaikan masalah seperti yang dilakukan oleh para ahli [7].

\section{FMEA}

FMEA adalah suatu cara dimana suatu bagian atau proses yang mungkin gagal memenuhi suatu spesifikasi, menciptakan cacat atau ketidaksesuaian dan dampaknya pada pelanggan bila mode kegagalan itu tidak dicegah dan dikoreksi [8]. Menurut kegunaanya, FMEA dapat dibedakan menjadi tiga jenis yaitu FMEA sistem, FMEA desain, dan FMEA proses. Keuntungan dari penggunaan FMEA adalah untuk meningkatkan kualitas, membantu meningkatkan kepuasan pada konsumen, dan mendokumentasikan tindakan yang harus diambil untuk mengurangi resiko.

\section{Die Casting}

Die casting adalah proses menginjeksi logam cair dengan tekanan tinggi ke dalam rongga cetakan. Peralatan die casting itu sendiri ditemukan pada tahun 1838 yang ditujukan untuk industri 
percetakan. Berdasarkan dari prosesnya, die casting dibedakan menjadi dua yaitu hot chamber machine dan cold chamber machine [9].

\section{Aluminium}

Nama aluminium diambil dari bahasa Latin yaitu alumen atau alum. Aluminium itu sendiri ditemukan sebagai unsur oleh Sir Humpherey Davy pada tahun 1809 dan direduksi untuk pertama kalinya sebagai logam oleh H. C. Oersted di tahun 1825. Pada tahun 1886, Heroult (Perancis) dan Hall (Amerika) secara industri telah memperoleh logam aluminium dari alumina dengan cara elektrolisa dari garamnya yang terfusi. Hingga saat ini proses Heroult Hall masih digunakan dalam produksi aluminium. Penggunaan aluminium itu sendiri sebagai logam tiap tahunnya pada urutan kedua setelah besi dan baja [10].

\section{Zinc}

Logam zinc dimanfaatkan sebagai bahan baku kuningan sedangkan zinc oksida dimanfaatkan dalam bidang pengobatan. Pemanfaatan zinc sebagai zat anti korosif merupakan salah satu aplikasi yang paling banyak dilakukan [11]. Dibandingkan dengan logam-logam lainnya, zinc merupakan logam yang memiliki titik lebur dan titik didih yang relatif rendah yaitu $410^{\circ} \mathrm{C}$ untuk titik leburnya dan $910^{\circ} \mathrm{C}$ untuk titik didihnya. Zinc sedikit kurang padat daripada besi dan memiliki struktur kristal heksagonal.

\section{METODOLOGI PENELITIAN}

Metodologi menjadi salah satu tahapan yang harus dilakukan sebelum melakukan penelitian tentang permasalahan utama yang ada. Sehingga penelitian dapat berjalan lebih teratur dan analisis terhadap permasalahan juga dapat terlaksana tanpa hambatan. Dengan demikian, maka tujuan yang diharapkan akan tercapai. Flowchart metodologi penelitian dapat dilihat pada Gambar 1.

\section{HASIL DAN PEMBAHASAN}

Dari data produk cacat maka diperoleh data produk yang memiliki tingkat persentasi yang cukup tinggi. Tingkat cacat produk dapat dilihat pada Gambar 2. Dapat diketahui bahwa tingkat kecacatan pada produk masih cukup tinggi dan terdapat lima produk yang memiliki jumlah cacat tertinggi selama enam bulan terakhir. Produk Angle Holder memiliki persentase tertinggi dengan nilai 31\%, Stay Front LH 0812 dengan nilai 28\%, Cover Lcylinder 24\%, Handle Lever 13\%, dan Cover Reed Valve dengan $10 \%$.

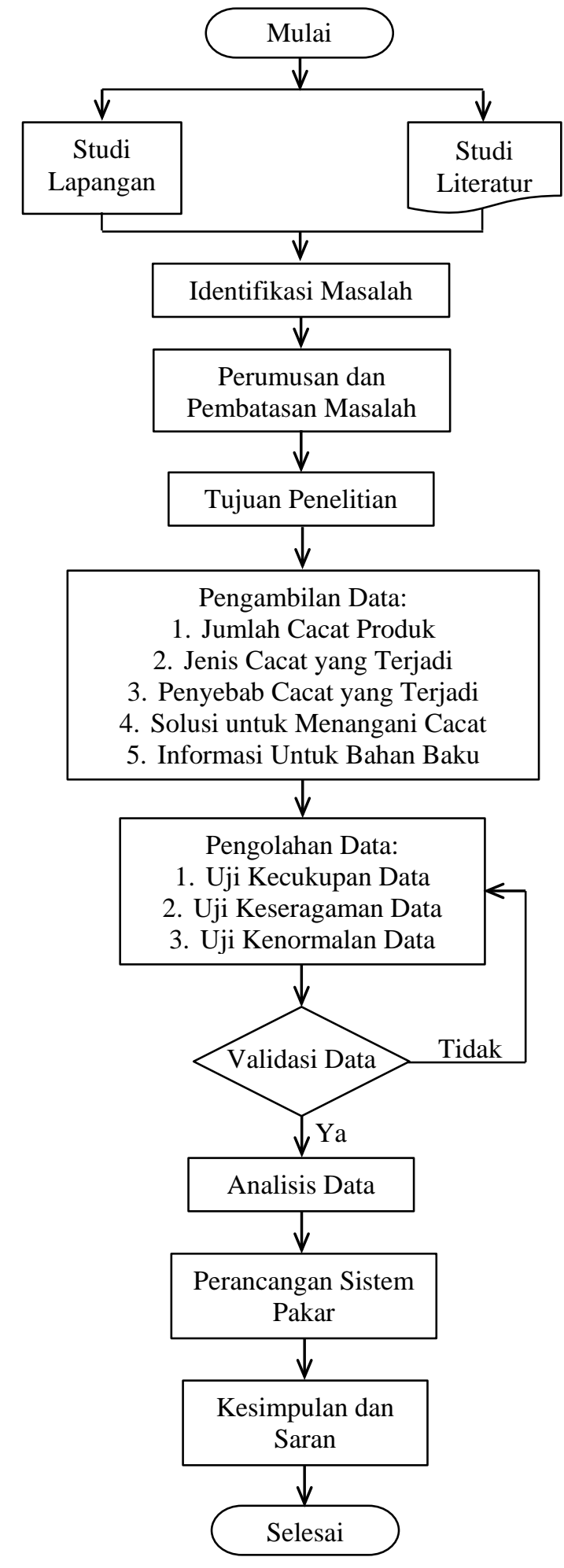

Gambar 1. Flowchart Metodologi Penelitian

Terdapat tiga jenis cacat yang terjadi yaitu cacat dimensi, visual dan keropos. Masing-masing dari ketiga cacat tersebut, terdapat pada setiap produk yang mengalami kecacatan. Namun jumlah jenis cacat yang terjadi berbeda-beda. Persentase tingkat kejadian jenis cacat dapat dilihat pada Gambar 3. Dari Gambar 3 maka diketahui bahwa jenis cacat yang paling sering muncul adalah cacat 
visual dengan persentase 54\%. Setelah diketahui jenis cacat yang paling sering muncul, selanjutnya dilakukan analisis terhadap data jumlah cacat produk yang terjadi setiap minggunya. Sebagai contoh, akan dilakukan analisis terhadap produk Handle Lever dengan menggunakan peta kendali p.

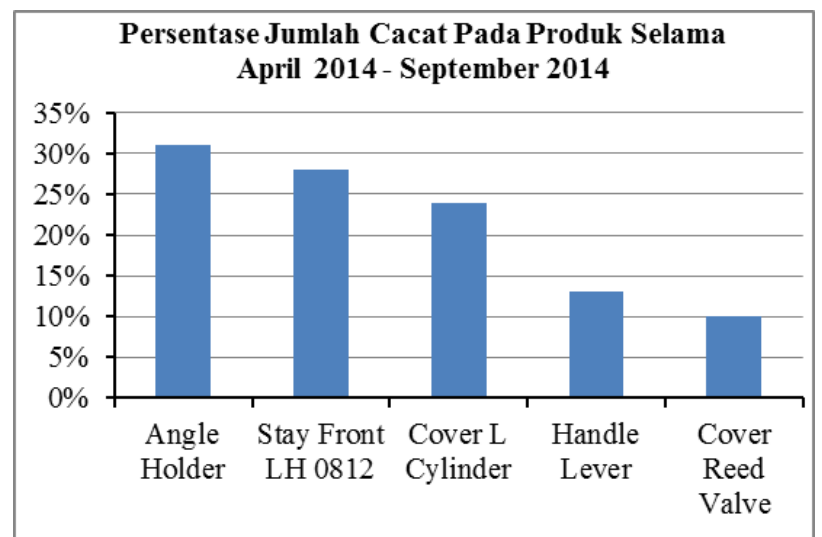

Gambar 2. Diagram Pareto Persentase Jumlah Cacat Keseluruhan

Dari peta kendali pada Gambar 4, maka dapat diketahui masih banyak data atau jumlah cacat produk yang berada diluar kendali. Oleh sebab itu diperlukannya tindakan lebih lanjut untuk mengetahui penyebab dari kecacatan yang terjadi pada produk tersebut. Analisis penyebab yang terjadi menggunakan diagram fishbone seperti dapat dilihat pada Gambar 5, Gambar 6 dan Gambar 7.

Dari data penyebab-penyebab terjadinya cacat yang telah disajikan dalam fishbone, maka diketahui penyebab cacat yang paling banyak disebabkan dari mesin dan human error. Selanjutnya tahap yang terakhir dilakukan sebelum perancangan sistem pakar, yaitu pembuatan FMEA (Tabel 1).
Dari tabel FMEA dapat diketahui apa saja yang dapat menjadi sumber kegagalan, kegagalan apa yang mungkin terjadi, penyebab dari kegagalan yang terjadi, pengaruh dari kegagalan yang terjadi, dan apa yang harus dilakukan untuk menangani dan menghindari terjadinya kegagalan.

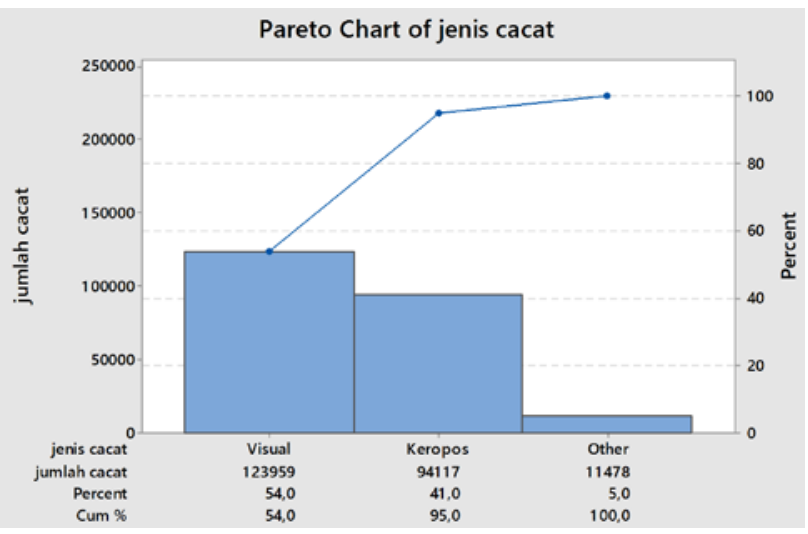

Gambar 3. Diagram Pareto Jenis dan Jumlah Cacat yang Sering Muncul

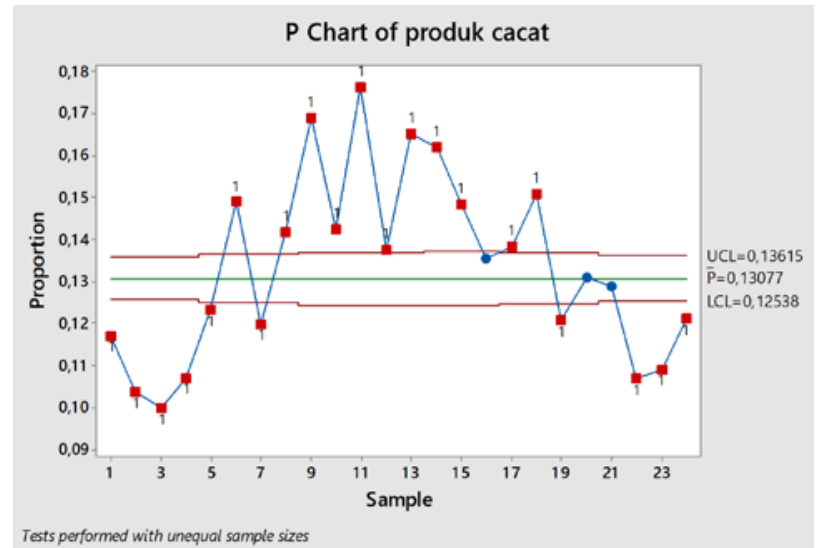

Gambar 4. Peta Kendali P Produk Handle Lever

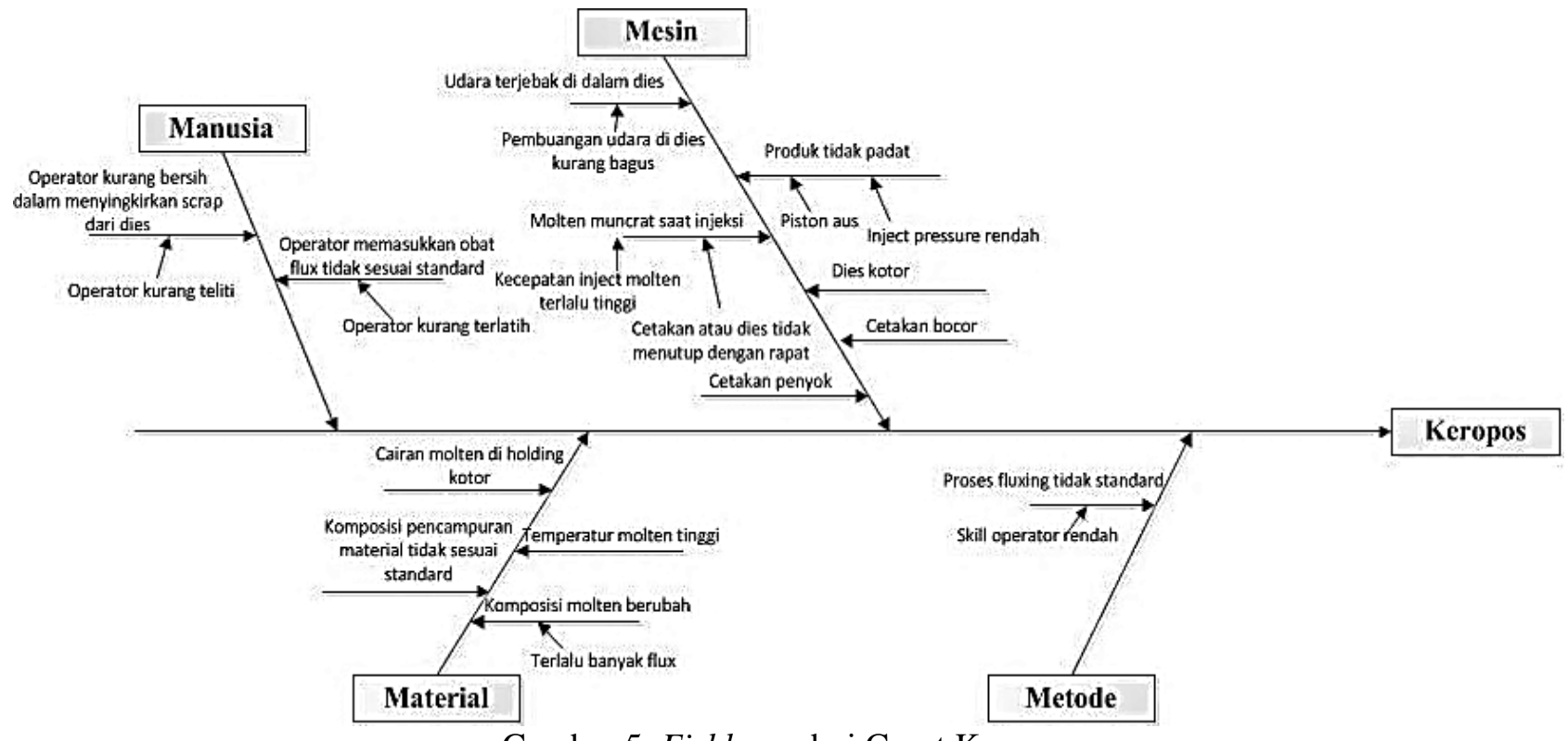

Gambar 5. Fishbone dari Cacat Keropos 


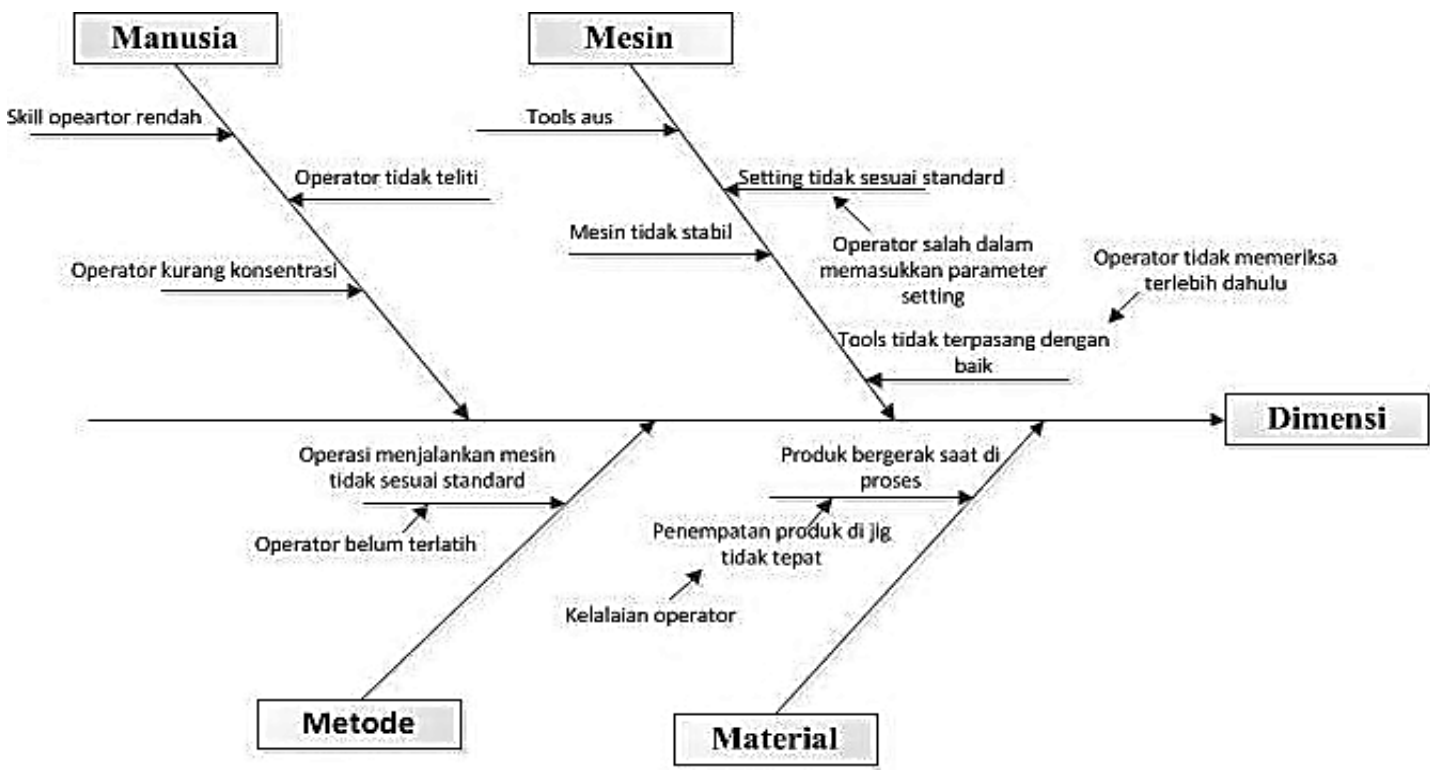

Gambar 6. Fishbone dari Cacat Dimensi

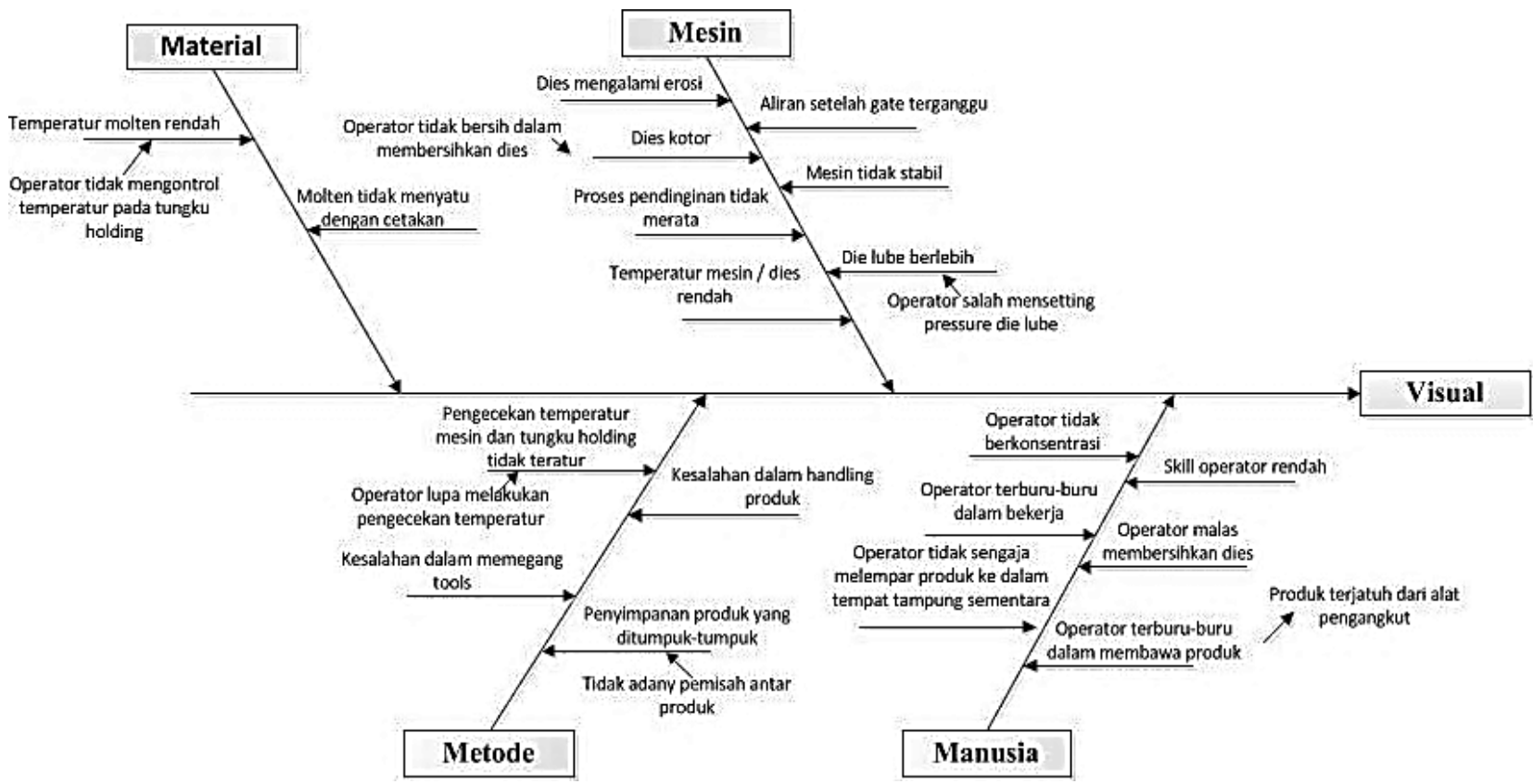

Gambar 7. Fishbone Dari Cacat Visual

Tabel 1. Tabel FMEA

\begin{tabular}{|c|c|c|c|c|c|c|c|c|c|}
\hline No & Proses & $\begin{array}{l}\text { Kegagalan yang } \\
\text { Mungkin Terjadi }\end{array}$ & Efek Kegagalan & Sev & Penyebab Kegagalan & Occ & Kontrol yang Dilakukan & Det & RPN \\
\hline \multirow{3}{*}{1} & \multirow{3}{*}{ Melting } & \multirow{3}{*}{ Molten Kotor } & $\begin{array}{l}\text { Part Keropos saat } \\
\text { destructive test }\end{array}$ & \multirow{3}{*}{3} & $\begin{array}{l}\text { Komposisi molten tidak } \\
\text { standar }\end{array}$ & \multirow{3}{*}{5} & $\begin{array}{l}\text { Test sprecto sebelum } \\
\text { melting }\end{array}$ & \multirow{3}{*}{3} & \multirow{3}{*}{45} \\
\hline & & & $\begin{array}{l}\text { Timbul kebocoran } \\
\text { pada part }\end{array}$ & & $\begin{array}{l}\text { Proses Fluxing tidak } \\
\text { standar } \\
\end{array}$ & & $\begin{array}{l}\text { Test sprecto setelah } \\
\text { melting }\end{array}$ & & \\
\hline & & & $\begin{array}{l}\text { Visual pada part tidak } \\
\text { standar }\end{array}$ & & $\begin{array}{l}\text { Ratio scrap saat proses } \\
\text { melting terlalu banyak }\end{array}$ & & $\begin{array}{l}\text { Test belah setelah } \\
\text { fluxing }\end{array}$ & & \\
\hline \multirow{5}{*}{2} & \multirow{5}{*}{ Casting } & \multirow[b]{2}{*}{ Keropos } & $\begin{array}{l}\text { Visual part tidak } \\
\text { padat }\end{array}$ & \multirow[b]{2}{*}{3} & $\begin{array}{l}\text { Pressure mesin kurang } \\
\text { Supply molten kurang } \\
\end{array}$ & \multirow[b]{2}{*}{5} & $\begin{array}{l}\text { Destructive test produk } \\
\text { setelah casting }\end{array}$ & \multirow[b]{2}{*}{5} & \multirow[b]{2}{*}{75} \\
\hline & & & $\begin{array}{l}\text { Inner quality tidak } \\
\text { standar }\end{array}$ & & $\begin{array}{l}\text { Molten kotor } \\
\text { Mixing ratio tidak } \\
\text { sesuai standart }\end{array}$ & & $\begin{array}{l}\text { Tensile test setelah } \\
\text { casting }\end{array}$ & & \\
\hline & & \multirow{3}{*}{ Cacat Visual } & \multirow{3}{*}{$\begin{array}{l}\text { Visual produk tidak } \\
\text { standar }\end{array}$} & \multirow{3}{*}{3} & $\begin{array}{l}\text { Performa mesin } \\
\text { menurun }\end{array}$ & \multirow{3}{*}{7} & $\begin{array}{l}\text { Membersihkan dies } \\
\text { sebelum dan sesudah }\end{array}$ & \multirow{3}{*}{5} & \multirow{3}{*}{105} \\
\hline & & & & & Human error & & digunakan & & \\
\hline & & & & & $\begin{array}{l}\text { Gangguan pada dies } \\
\text { Aliran gate terganggu }\end{array}$ & & $\begin{array}{l}\text { Pengecekan mesin } \\
\text { sebelum dijalankan }\end{array}$ & & \\
\hline
\end{tabular}


Lanjutan Tabel 1. Tabel FMEA

\begin{tabular}{|c|c|c|c|c|c|c|c|c|c|}
\hline No & Proses & $\begin{array}{c}\text { Kegagalan yang } \\
\text { Mungkin Terjadi }\end{array}$ & Efek Kegagalan & Sev & Penyebab Kegagalan & Occ & Kontrol yang Dilakukan & Det & RPN \\
\hline \multirow{4}{*}{3} & \multirow{4}{*}{$\begin{array}{l}\text { Fini } \\
\text { Shing }\end{array}$} & \multirow{4}{*}{ Dimensi Out } & Dimensi lubang hasil & & Jig tidak fix & 3 & \multirow{4}{*}{$\begin{array}{l}\text { Check dimensi setelah } \\
\text { proses }\end{array}$} & \multirow{4}{*}{3} & \multirow{4}{*}{27} \\
\hline & & & bor over & & $\begin{array}{l}\text { Kapabilitas mesin tidak } \\
\text { stabil }\end{array}$ & & & & \\
\hline & & & \multirow{2}{*}{$\begin{array}{l}\text { Tidak bisa assy } \\
\text { dengan produk lain }\end{array}$} & & Tool aus & & & & \\
\hline & & & & & $\begin{array}{l}\text { Setting offset mesin } \\
\text { tidak tepat }\end{array}$ & & & & \\
\hline
\end{tabular}

\section{PERANCANGAN PROGRAM SISTEM PAKAR}

Dari hasil pengolahan data maka tahap selanjutnya yang dapat dilakukan adalah perancangan sistem pakar. Sistem pakar yang dirancang adalah untuk pengendalian kualitas pada divisi bahan baku, divisi proses produksi, dan divisi produk jadi. Berkaitan dengan usaha untuk mengurangi tingkat kecacatan pada produk, memenuhi kebutuhan perusahaan akan adanya sistem pengendalian kualitas yang baru, dan untuk meminimalisasi ketergantungan terhadap seorang pakar sehingga karyawan lama maupun karyawan baru dapat mencari tahu kiranya apa saja penyebab dari kecacatan yang ada, dapat mengatasi masalah yang ada dengan segera, dan mendapatkan pengetahuan seputar dengan keseluruhan proses produksi yang berlangsung.

Dalam perancangan sistem pakar, interaksi antar pembangun sistem pakar, dan pakar harus saling berinteraksi dengan didukung juga oleh peralatan dalam membangun sistem pakar. Elemen-elemen dalam perancangan sistem pakar yang ditujukan untuk sistem pendukung pengendalian pada PT. SJA dapat dilihat pada Tabel 2.

Struktur dasar untuk sistem yang dikembangkan adalah lingkungan pengembangan yaitu lingkungan tempat dimana pembangun sistem pakar mengumpulkan pengetahuan-pengetahuan dasar yang akan digunakan untuk perancangan sistem pakar dan lingkungan konsultasi yaitu lingkungan dimana pengguna dari sistem pakar mendapatkan informasi dari pengetahuan yang disimpan dalam basis pengetahuan. Skema dari struktur dasar dapat dilihat pada Gambar 8. Pada basis pengetahuan untuk dasar perancangan sistem pakar yang ditujukan sebagai pendukung sistem pengendalian kualitas di PT. SJA yaitu meliputi karakteristik dari kualitas tiap proses. Karakteristik kualitas tersebut dapat dilihat pada Gambar 9.

Tabel 2. Elemen-elemen Sistem Pakar

\begin{tabular}{|c|c|c|}
\hline No & Elemen & Tugas \\
\hline \multirow{9}{*}{1} & \multirow{9}{*}{$\begin{array}{l}\text { Pakar, jumlah } \\
\text { pakar yang } \\
\text { dilibatkan } 7 \\
\text { orang }\end{array}$} & $\begin{array}{l}\text { Melibatkan pakar yang khusus menangani bahan baku, proses produksi, dan pengendalian } \\
\text { kualitas di PT.SJA yaitu: }\end{array}$ \\
\hline & & Pakar 1: Kepala bagian material \\
\hline & & Pakar 2: Kepala bagian melting dan casting \\
\hline & & Pakar 3: Kepala bagian finishing \\
\hline & & Pakar 4: Kepala bagian pengendalian kualitas \\
\hline & & Pakar 5: Kepala bagian machining \\
\hline & & Pakar lainnya yang dilibatkan dalam hal material dan die casting yaitu: \\
\hline & & Pakar 6: Japan International Standart 2005 \\
\hline & & Pakar 7: ASM Metal Handbook Casting \\
\hline 2 & $\begin{array}{l}\text { Pembangunan } \\
\text { sistem pakar }\end{array}$ & $\begin{array}{l}\text { Pembangunan sistem pakar dalam hal ini adalah mengumpulkan data, informasi langsung } \\
\text { dari pakar, dan menggunakan kerangka standarisasi dalam perancangan sistem pakar untuk } \\
\text { mendukung sistem pengendalian kualitas pada PT. SJA }\end{array}$ \\
\hline \multirow{3}{*}{3} & \multirow{3}{*}{ Pengguna } & Pengguna sistem pakar yang dirancang \\
\hline & & $\begin{array}{l}\text { Pengguna 1: Pengguna primer yaitu para kepala bagian material, melting, casting, finishing, } \\
\text { machining, dan QC yang ditujukan untuk membantu serta mendukung dalam hal } \\
\text { pengendalian kualitas }\end{array}$ \\
\hline & & $\begin{array}{l}\text { Pengguna 2: pengguna sekunder yaitu operator maupun para karyawan yang ditujukan untuk } \\
\text { membantu para operator dan karyawan dalam membantu para kepala bagaian dalam } \\
\text { menangani pengendalian kualitas saat para kepala bagian berhalangan dalam menjalankan } \\
\text { tugas pengendalian }\end{array}$ \\
\hline 4 & Elemen kerja & $\begin{array}{l}\text { Pembangunan sistem yang membantu dalam mengintegrasikan kedalam komputerisasi, tool } \\
\text { builder menyediakan alat pembangunan yang dibutuhkan dan vendor yang memberikan } \\
\text { masukan }\end{array}$ \\
\hline
\end{tabular}




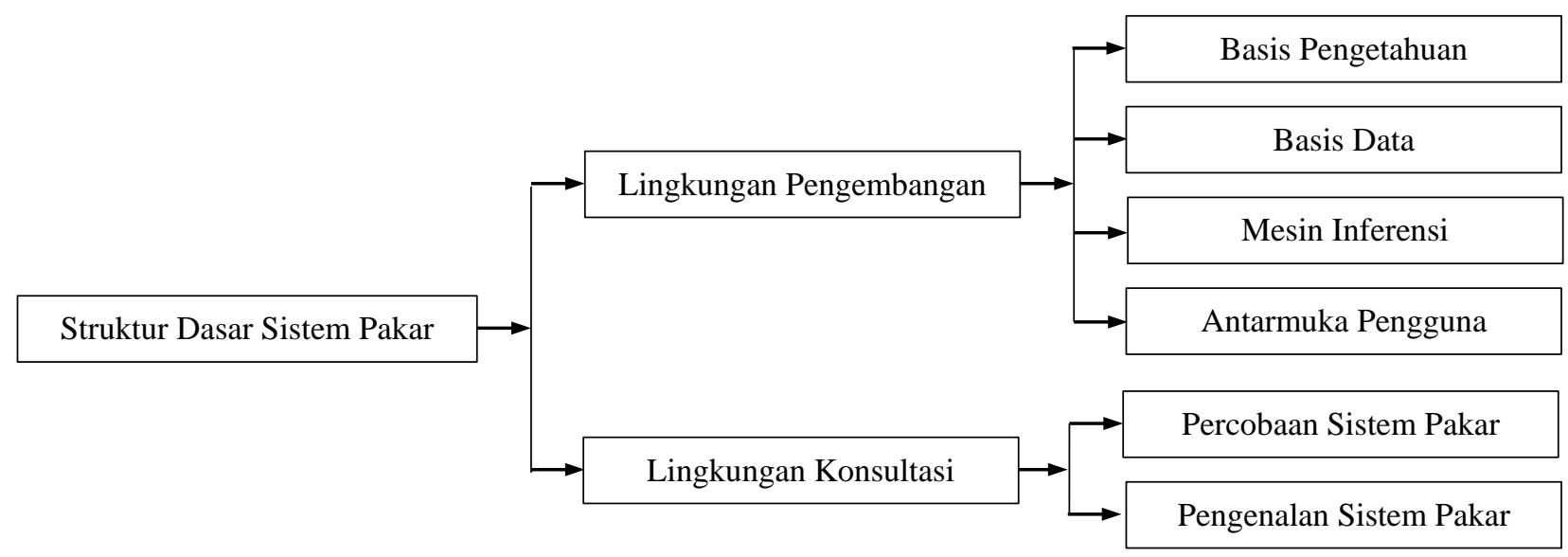

Gambar 8. Struktur Dasar Sistem Pakar

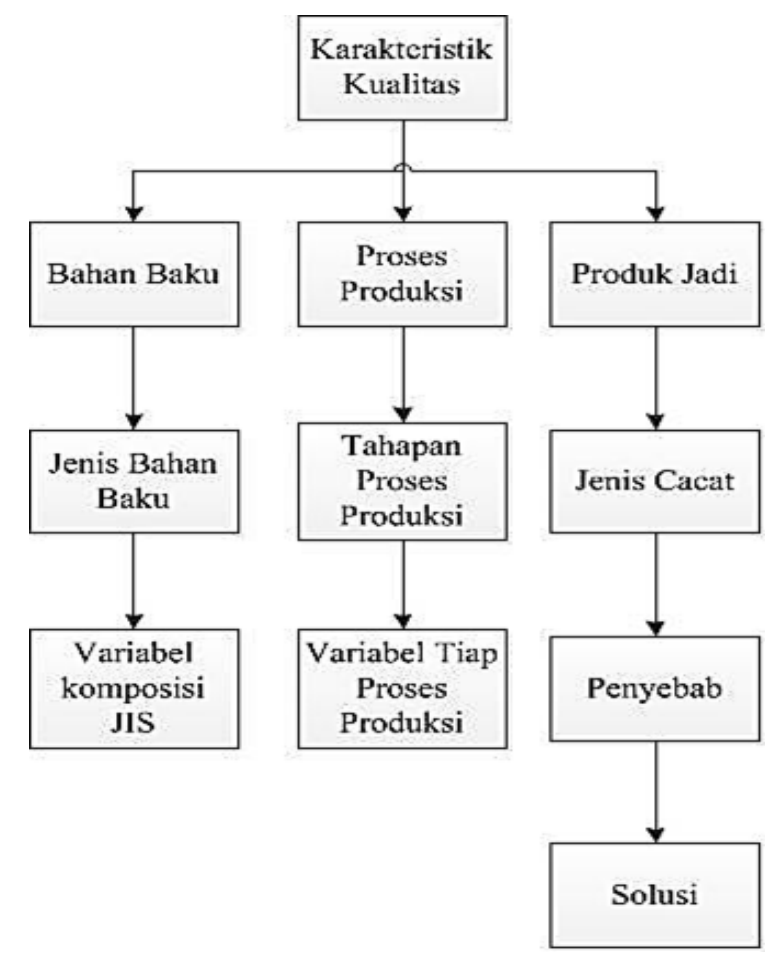

Gambar 9. Karakteristik Kualitas pada Basis Pengetahuan

Basis data merupakan bagian yang mengandung semua fakta yang ada pada sistem yang dirancang. Basis data yang ada pada sistem pakar pendukung pengendalian kualitas pada PT. SJA tidak hanya memuat tentang atribut penilaian saja yang merupakan basis data untuk menentukan diterima atau ditolaknya suatu input oleh user yang ditentukan dengan suatu persyaratan yang ada. Selain data tentang penilaian tersebut, basis data pada program ini juga tentang informasi-informasi dan kesimpulan yang didapat berdasarkan dengan input yang dipilih dan dimasukkan oleh user. Tabel atribut penilaian dan informasi pada basis data dapat dilihat pada Tabel 3 dan Tabel 4.

Tabel 3. Contoh Tabel Atribut Penilaian Dalam Basis Data

\begin{tabular}{|c|c|c|c|}
\hline \multirow[b]{2}{*}{ No. } & \multirow{2}{*}{$\begin{array}{c}\text { Atribut } \\
\text { Penilaian }\end{array}$} & \multicolumn{2}{|c|}{ Keterangan } \\
\hline & & $\begin{array}{c}\text { Tingkat } \\
\text { Kualitas }\end{array}$ & Persyaratan \\
\hline \multicolumn{4}{|c|}{ Bahan Baku - HD 4} \\
\hline \multirow[t]{2}{*}{1.} & $\mathrm{Cu}$ & Diterima & $2,5-4,0$ \\
\hline & & Ditolak & $<2,5$ atau $>4,0$ \\
\hline \multirow[t]{2}{*}{2.} & $\mathrm{Si}$ & Diterima & 1 \\
\hline & & Ditolak & $<1$ atau $>1$ \\
\hline \multirow[t]{2}{*}{3.} & $\mathrm{Mg}$ & Diterima & $4,0-5,5$ \\
\hline & & Ditolak & $<4,0$ atau $>5,5$ \\
\hline \multirow[t]{2}{*}{4.} & $\mathrm{Zn}$ & Diterima & 0,1 \\
\hline & & Ditolak & $<0,1$ dan $>0,1$ \\
\hline \multirow[t]{2}{*}{5.} & $\mathrm{Fe}$ & Diterima & 0,5 \\
\hline & & Ditolak & $<0,5$ atau $>0,5$ \\
\hline \multirow[t]{2}{*}{6.} & $\mathrm{Mn}$ & Diterima & 0,4 \\
\hline & & Ditolak & $<0,4$ atau $>0,4$ \\
\hline \multirow[t]{2}{*}{7.} & $\mathrm{Ni}$ & Diterima & 0,4 \\
\hline & & Ditolak & $<0,4$ atau $>0,4$ \\
\hline \multirow[t]{2}{*}{8.} & Sn & Diterima & 0,1 \\
\hline & & Ditolak & $<0,1$ atau $>0,1$ \\
\hline
\end{tabular}

Hasil yang telah didapat pada basis data kemudian akan diubah menjadi suatu aturan sebagai mekanisme logika dalam perancangan antarmuka pengguna. Adapun tampilan antarmuka pengguna dari sistem pakar dapat dilihat pada Gambar 9, Gambar 10 dan Gambar 11. 
Tabel 4. Atribut Informasi dalam Basis Data

\begin{tabular}{|c|c|c|}
\hline No & Atribut Informasi & Keterangan \\
\hline \multicolumn{3}{|r|}{ Proses Produksi -Melting } \\
\hline 1. & Handle Lever & Bahan baku yang digunakan HD 4 dengan perbandingan virgin $60 \%$ dan scrap $40 \%$ \\
\hline 2. & Cover Reed Valve & Bahan baku yang digunakan ADC 12 dengan perbandingan virgin 50\% dan scrap 50\% \\
\hline 3. & Cover L Cylinder & Bahan baku yang digunakan ADC 12 dengan perbandingan virgin 60\% dan scrap 40\% \\
\hline 4. & Angle Holder & Bahan baku yang digunakan ADC 12 dengan perbandingan virgin $50 \%$ dan scrap $50 \%$ \\
\hline 5. & Stay Front LH 0812 & Bahan baku yang digunakan ADC 12 dengan perbandingan virgin 50\% dan scrap 50\% \\
\hline \multicolumn{3}{|r|}{ Proses Produksi - Fluxing } \\
\hline 1. & Angle Holder & $\begin{array}{l}\text { Obat flux : Cover C-008 AH (350 gram) dan Cover C-661 (350 gram) } \\
\text { Obat degassing : Cover } 100 \text { BH (250 gram) }\end{array}$ \\
\hline 2. & Cover Reed Valve & $\begin{array}{l}\text { Obat flux : Cover C-008 AH (350 gram) dan Cover C-661 (350 gram) } \\
\text { Obat degassing : Cover } 100 \mathrm{BH} \text { (250 gram) }\end{array}$ \\
\hline 3. & Handle Lever & $\begin{array}{l}\text { Obat flux : Cover C-008 AH (350 gram) dan Cover C-661 (350 gram) } \\
\text { Obat degassing : Cover } 100 \mathrm{BH} \text { ( } 250 \text { gram) }\end{array}$ \\
\hline 4. & Cover L Cylinder & $\begin{array}{l}\text { Obat flux : Cover C-008 AH (350 gram) dan Cover C-661 (350 gram) } \\
\text { Obat degassing : Cover } 100 \text { BH (250 gram) }\end{array}$ \\
\hline 5. & Stay Front LH 0812 & $\begin{array}{l}\text { Obat flux : Cover C-008 AH (350 gram) dan Cover C-661 (350 gram) } \\
\text { Obat degassing : Cover } 100 \text { BH ( } 250 \text { gram) }\end{array}$ \\
\hline \multicolumn{3}{|r|}{ Proses Produksi - Finishing } \\
\hline 1. & Stay Front LH 0812 & $\begin{array}{l}\text { proses potong, alat tang potong } \\
\text { proses boring, alat Ø12 (1550-1980 r/min) } \\
\text { proses boring, alat Ø10,5 (1550-1980 r/min) } \\
\text { proses boring, alat Ø4 (2700-3400 r/min) } \\
\text { proses amplas gate, alat amplas roll P40 (2070 r/min) } \\
\text { proses kikir bintik, alat kikir 6" } \\
\text { proses amplas, amplas flap wheel \#180 (2070 r/min) } \\
\text { proses semprot, alat selang dan angin } \\
\text { proses dempul, sanpolac } \\
\text { proses amplas, alat amplas \#40 (2070 r/min) }\end{array}$ \\
\hline 2. & Handle Lever & $\begin{array}{l}\text { proses slitting, alat slitting saw }(1840 \mathrm{r} / \mathrm{min}) \\
\text { proses end mill, alat Ø6,4 }(1420-1880 \mathrm{r} / \mathrm{min}) \\
\text { proses end mill, alat Ø8,5 }(1420-1880 \mathrm{r} / \mathrm{min}) \\
\text { proses slitting, alat slitting saw } 45 "(1840 \mathrm{r} / \mathrm{min}) \\
\text { proses kikir, alat kikir 8" } \\
\text { proses amplas gate, alat amplas \#180 }(1740 \mathrm{r} / \mathrm{min}) \\
\text { proses amplas body, alat flaw wheel \#220 (1740 r/min) }\end{array}$ \\
\hline 3. & Cover Reed Valve & $\begin{array}{l}\text { proses potong, alat tang potong } \\
\text { proses amplas, alat amplas \#40 (2780 r/min) } \\
\text { proses kikir, alat kikir 8" } \\
\text { proses boring, alat Ø5,8 }(1320-2500 \mathrm{r} / \mathrm{min}) \\
\text { proses grinding, alat grinding } \varnothing 8(2800 \mathrm{r} / \mathrm{min})\end{array}$ \\
\hline 4. & Cover L Cylinder & $\begin{array}{l}\text { proses CNC, mesin CNC } \\
\text { proses kikir, alat kikir 8" } \\
\text { proses boring, alat Ø6,5 }(1420-1880 \mathrm{r} / \mathrm{min}) \\
\text { proses hole, alat Ø86 }(1550-1980 \mathrm{r} / \mathrm{min}) \\
\text { proses hole, alat Ø80,3 }(1550-1980 \mathrm{r} / \mathrm{min}) \\
\text { proses hole, alat Ø76,3 (1420-1880 r/min) }\end{array}$ \\
\hline 5. & Angle Holder & $\begin{array}{l}\text { proses grinding, alat batu gerinda (2800 r/min) } \\
\text { proses kikir, alat kikir 8" } \\
\text { proses amplas, alat amplas grade } \mathrm{P} 40(2070 \mathrm{r} / \mathrm{min}) \\
\text { proses boring, alat bor Ø11 }(1170-2100 \mathrm{r} / \mathrm{min}) \\
\text { proses chamfer, alat bor } Ø 5,5(1420-1880 \mathrm{r} / \mathrm{min})\end{array}$ \\
\hline \multicolumn{3}{|r|}{ Produk Jadi - Cover Reed Valve } \\
\hline 1. & $\begin{array}{l}\text { Keropos bintik } \\
\text { hitam }\end{array}$ & $\begin{array}{l}\text { Penyebab : molten kotor } \\
\text { solusi : lakukan kembali proses fluxing, pastikan proses fluxing berjalan sesuai standard }\end{array}$ \\
\hline \multirow[t]{2}{*}{2.} & \multirow[t]{2}{*}{$\begin{array}{l}\text { Keropos bintik putih } \\
\text { kecil }\end{array}$} & $\begin{array}{l}\text { Penyebab : Adanya udara yang terjebak di dalam produk dikarenakan oleh Pembuangan udara } \\
\text { pada dies kurang bagus, kondisi dies kotor, pressure inject tinggi (di atas } 130 \text { Psi) karena setting } \\
\text { yang salah atau performa mesin berkurang }\end{array}$ \\
\hline & & $\begin{array}{l}\text { solusi : penggantian dies baru, meminta pihak supplierdies agar mendesign ulang atau } \\
\text { memperbaiki design pembuangan udara pada dies,setting pressure inject sesuai standard (100-130 } \\
\text { Psi), pemeriksaan dan perbaikan mesin oleh operator mesin }\end{array}$ \\
\hline \multirow[t]{2}{*}{3.} & \multirow[t]{2}{*}{$\begin{array}{l}\text { Keropos bintik putih } \\
\text { besar }\end{array}$} & $\begin{array}{l}\text { Penyebab : pressure inject terlalu tinggi (diatas } 130 \mathrm{Psi} \text { ), dies tidak menutup dengan rapat, } \\
\text { temperatur molten tinggi (di atas } 690 \mathrm{C} \text { ), terjadi kebocoran pada dies, piston aus }\end{array}$ \\
\hline & & $\begin{array}{l}\text { Solusi : setting pressure inject sesuai standard (100-130 Psi), pemeriksaan dan perbaikan mesin } \\
\text { oleh operator mesin, pengaturan setting load meter sesuai standard (80\%-90\%), temperatur } \\
\text { moltenholding sesuai standard yaitu } 680 \text { C - } 690 \text { C, penggantian piston oleh operator mesin }\end{array}$ \\
\hline
\end{tabular}


Lanjutan Tabel 4. Atribut Informasi Dalam Basis Data

\begin{tabular}{|c|c|c|}
\hline No & Atribut Informasi & Keterangan \\
\hline \multirow[t]{2}{*}{4.} & \multirow[t]{2}{*}{ Lecet } & $\begin{array}{l}\text { penyebab: Penyimpanan produk yang bertumpuk dan tidak adanya pemisah antar produk, operator } \\
\text { tidak berhati-hati dalam pengangkutan dan penyimpanan produk }\end{array}$ \\
\hline & & $\begin{array}{l}\text { solusi: pemberian pembatas (plastik penutup) antar produk saat disimpan, operator harus berhati- } \\
\text { hati saat membawa produk atau saat akan menyimpan produk }\end{array}$ \\
\hline \multirow[t]{2}{*}{5.} & \multirow[t]{2}{*}{ Terpukul } & $\begin{array}{l}\text { penyebab: kesalahan pada handling produk dan tools, operator tidak berhati-hati dalam } \\
\text { memisahkan overflow pada produk }\end{array}$ \\
\hline & & $\begin{array}{l}\text { solusi: memasang one point lesson untuk cara holding tools dan produk, mengingatkan kembali } \\
\text { para operator untuk selalu berkonsentrasi saat bekerja }\end{array}$ \\
\hline \multirow[t]{2}{*}{6.} & \multirow[t]{2}{*}{ Flowline } & $\begin{array}{l}\text { penyebab: temperatur molten rendah, die lube berlebih, temperatur dies rendah, aliran setelah gate } \\
\text { terganggu }\end{array}$ \\
\hline & & $\begin{array}{l}\text { solusi: pastikan temperatur molten sesuai standar yaitu } 680 \text { C - } 690 \text { C, setting die lube sesuai } \\
\text { standar (1,5 s), setting temperatur dies sesuai standar (140 C), pemeriksaan dan perbaikan gate } \\
\text { oleh operator (dengan penambalan bila gate mengalami erosi) }\end{array}$ \\
\hline \multirow[t]{2}{*}{7.} & \multirow[t]{2}{*}{ Kempot } & $\begin{array}{l}\text { penyebab: mesin mengalami penurunan performa, pendinginan tidak merata sehingga } \\
\text { pendinginan terjadi hanya pada permukaan produk }\end{array}$ \\
\hline & & solusi: pemeriksaan dan perbaikan mesin oleh operator mesin \\
\hline \multirow[t]{2}{*}{8.} & \multirow[t]{2}{*}{ Kasar } & penyebab : dies mengalami erodi \\
\hline & & solusi: penggantian dies baru \\
\hline \multirow[t]{2}{*}{9.} & \multirow[t]{2}{*}{ Retak } & penyebab : dies kotor, dies mengalami keretakan \\
\hline & & solusi: membersihkan dies selalu (setelah atau sebelum digunakan), penggantian dies baru \\
\hline \multirow[t]{2}{*}{10.} & \multirow[t]{2}{*}{ Dimensi } & $\begin{array}{l}\text { penyebab: Tools aus, setting alat tidak sesuai standard, mesin mengalami penurunan performa, } \\
\text { tools tidak terpasang dengan baik, produk tidak terpasang pas pada jig proses } \\
\text { Solusi penggantia tools baru, setting disesuaikan dengam }\end{array}$ \\
\hline & & $\begin{array}{l}\text { Solusi: Penggantian tools baru, setting alat disesuaikan dengan standar (setting pada divisi setting } \\
\text { dapat dilihat pada program pakar, perbaikan mesin oleh operator mesin, pemasangan tools dengan } \\
\text { baik dan benar, memastikan tools selalu terpasang dengan baik sebelum menjalankan mesin, } \\
\text { peletakkan produk pada jig proses dengan baik dan benar, memastikan produk sudah terpasang } \\
\text { dengan baik dan pas pada jig proses sebelum memulai proses }\end{array}$ \\
\hline
\end{tabular}

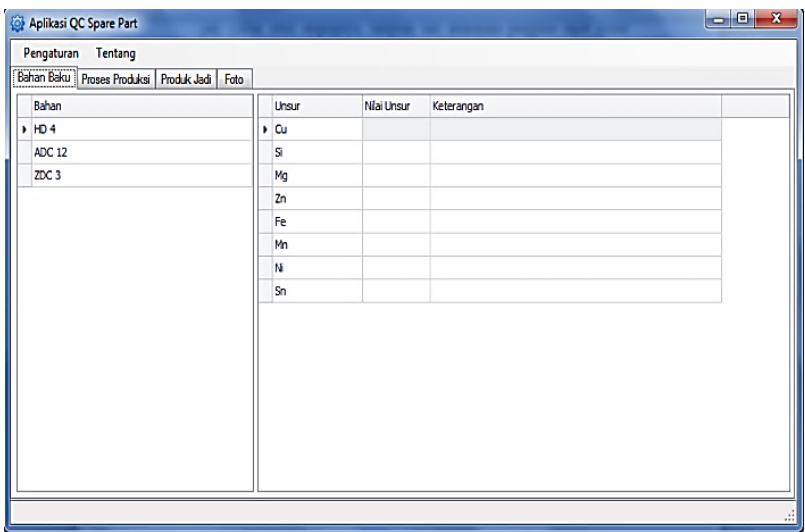

Gambar 9. Antarmuka Pengguna Form Bahan Baku

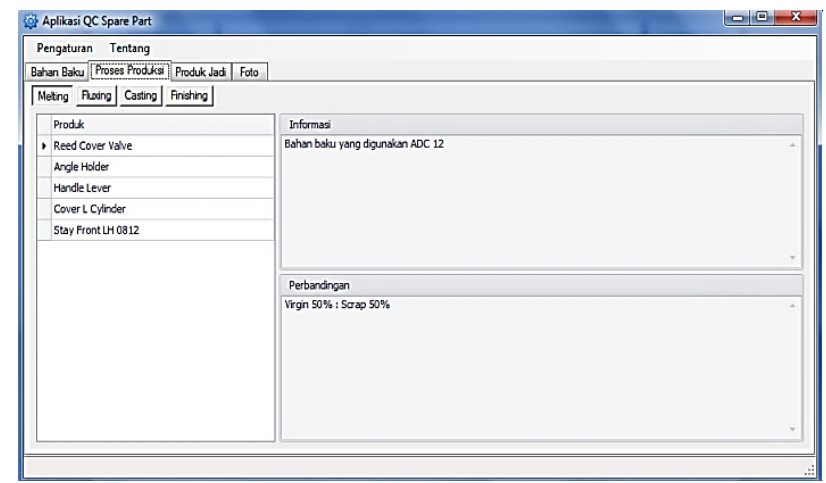

Gambar 10. Antarmuka Pengguna Form Proses Produksi

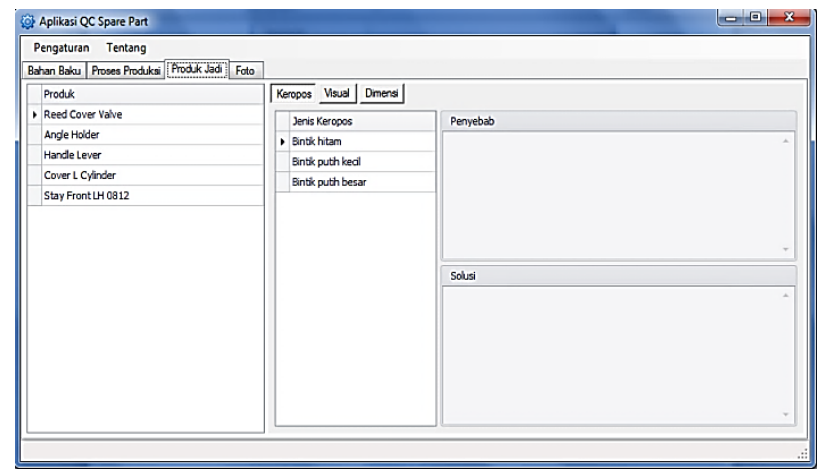

Gambar 11. Antarmuka Pengguna Form Bagian Produk Jadi

\section{KESIMPULAN}

Berdasarkan hasil penelitian yang dilakukan dan analisis terhadap permasalahan pengendalian kualitas di PT. SJA, maka dapat disimpulkan hasil dari penelitian ini adalah terdapat tiga jenis cacat yang ada pada PT. SJA, yaitu cacat visual, keropos, dan dimensi. Masing-masing memiliki faktor penyebab yang berbeda-beda. Ada beberapa hal yang harus diperhatikan dalam pengendalian kualitas pada bahan baku dan proses produksi yaitu komposisi setiap bahan baku yang harus sesuai dengan standard JIS (Japan International Standard), komposisi pencampuran antara 
bahan baku virgin dengan scrap, komposisi obat flux dan degassing untuk setiap bahan baku, waktu yang dibutuhkan untuk melakukan proses fluxing, penilaian sampel pada divisi casting, dan proses finishing yang harus dialami oleh setiap produk serta alat yang dibutuhkan untuk masing-masing proses finishing yang terjadi. Rancangan sistem pakar yang telah dibuat disesuaikan dengan hal-hal apa saja yang perlu diperhatikan pada setiap proses yang ada mulai dari bahan baku hingga proses finishing, penyebab suatu kecacatan dapat terjadi, solusi dalam menangani jenis cacat yang terjadi. Sehingga program sistem pakar ini sudah dapat mendukung proses pengendalian kualitas pada PT. SJA.

\section{DAFTAR PUSTAKA}

[1] Hariastuti, Ni Luh Putu, 2010, Pengendalian Kualitas Produk Dalam Upaya Menurunkan Tingkat Kegagalan Produk Jadi, Institut Teknologi Adhitama Surabaya.

[2] Rossian, Jennifer, 2011, Implementasi Sistem Pendukung Pengambilan Keputusan Berbasis Sistem Pakar Dalam Penilaian Kualiats Bahan Baku, Proses Pengolahan, Dan Produk Akhir PT. Red Ribbon Indonesia.
[3] Yuliana, Shelly, 2005, Sistem Pengendalian Kualitas Dengan Bantuan Expert System Untuk Menurunkan Tingkat Kecacatan Produk, Jurnal Teknik Industri Universtitas Kristen Petra, Vol 7.

[4] Feigenbaum, A.V., 1983, Total Quality Control, Third Edition, New York: Mcgraw-Hill, Inc.

[5] Montgomery, D. C. 2005. Introduction to Statistical Quality Control 5th Edition. New York: John Wiley and Sons, Inc.

[6] Sparague, R. H., and Watson H. J., 1993, Decision Support Systems: Putting Theory Into Practice, Englewood Clifts, N. J., Prentice Hall.

[7] Kusumadewi, 2003, “Artifical Intelligence (Teknik dan Aplikasi)”, Edisi I Graha Ilmu, Yogyakarta.

[8] Crow, Kenneth, 2004, Failure Modes and Effects Analysis (FMEA), DRM Associates, USA. http://www.npdsolutions.com/fmea.html.

[9] Doehler, H., "Die Casting”, McGraw Hill Book Company, New York

[10] Surdia, Tata \& Saito, Shinroku, 2005, Pengetahuan Bahan Teknik, (cetakan keenam), Jakarta: Pradnya Paramita.

[11] Mohlis, J., 2006, http://www.chem_is_ try.org 